\title{
State Initiatives and the Role of Media in Mitigating Human Trafficking: A Case Study of Tea Plantation Workers of Sonitpur District in Assam
}

Saket Kumar Bhardwaj is a Research Scholar in the Department of Mass Communication and Journalism, Tezpur University.

Uttam Pegu is an Associate Professor in the Department of Mass Communication and Journalism, Tezpur University.

\section{Abstract}

The focus of this study is to evaluate the communication strategies adopted by various governments and non-government agencies working in Sonitpur district of Assam in an effort to tackle the ills of trafficking in human. As per the National Crime Records Bureau report, there were a total of 8,132 reported cases of Trafficking in 2016 across India, with 91 (1.12\%) cases from Assam. Assam is a state that has registered a total of $1,494(21.7 \%)$ trafficking cases in 2015 with Sonitpur district being one of the worst affected. There is a rapid increase in the number of missing adolescent children across the state. The study primarily deals with three important issues a) What is the current status of human trafficking in Assam, b) What are the several initiatives taken by government and non-government organizations? and c) What is the reach and effectiveness of those initiatives? This study basically reveals the need and importance of effective communication strategies adopted by government and Non-Government organization to deal with social ill like trafficking in human.

Key Words: Human Trafficking, Media, Communication Strategy, Sonitpur, Assam.

Trafficking is an evolving multidimensional and complex human problem that cannot be defined in simple terms. United Nations defines trafficking as "the recruitment, transportation, transfer, 


\section{6 / Saket Kumar Bhardwaj \& Uttam Pegu}

Salesian Journal of Humanities and Social Sciences, Vol. X, No. 1. (May 2019) ISSN: 0976-1861 | DOI: 10.51818/SJHSS.10.2019.55-67 | Page: 55-67,

Section: Article

harbouring or receipt of persons by means of threat or use of force or other forms of coercion, of abduction, of fraud, of deception, of the abuse of power or of a position of vulnerability or a giving or receiving of payments or benefits to achieve the consent of a person having control over another person, for the purpose of exploitation. Exploitation shall include, at a minimum, the exploitation of the prostitution of others or other forms of sexual exploitation, forced labour or service, slavery or practices similar to slavery, servitude or the removal of organs". Trafficking has been a scorching issue of the present civilization and it is identified as the fastest growing criminal industry of present era. Every year a huge number of men, Human and children become prey of the traffickers. Women trafficking is a phenomenon that has been and continues to be practiced for centuries now. According to Hoque, human trafficking is "like the global economic crisis, human trafficking is a global crisis that is inextricably linked to the current move of globalization in the sex industries involving women and children."1

Trafficking has no definite boundary, this can happen within a country, within state or internationally. The prime focus of trafficking is sexual exploitation and bondage labor but certain other issues are also related with this. Human trafficking is a major crime against humanity. Loss of freedom is one common experience shared by the victims of trafficking.

The International Labor Organization estimates that 1.2 million people are trafficked each year. Human trafficking is globally recognized as a major Human rights violation and this social evil is prevailing in each country present in this globe. With the growth of social research and the research in public relation has helped to bring this menace into focus and from the pervasiveness and ramification of this practice have risen to international prominence. ${ }^{2}$

\footnotetext{
${ }^{1}$ NMS Hoque, "Female Child Trafficking from Bangladesh: A New Form of Slavery", Canadian Social Sciences, (2010).

2 Alexis A. Aronowitz, Human Trafficking and Human Misery (Westport: Praeger Publishers, 2009).
} 
State Initiatives and the Role of Media in Mitigating Human Trafficking.. /57 Salesian Journal of Humanities and Social Sciences, Vol. X, No. 1. (May 2019) ISSN: 0976-1861 | DOI: 10.51818/SJHSS.10.2019.55-67 | Page: 55-67, Section: Article

\section{Can Communication Strategies and Media Help Control Trafficking?}

Wilbur Schram was the first who recognized that communication could play an important role in the national development of the third world countries. He believed that mass media could save the lives of the people by supplementing the information resources and exposing people for learning opportunity. ${ }^{3}$ The general notion about development communication refers to bringing development plans (usually prepared by government and nongovernmental organizations) to people for whom they are intended. General role of development communication is to educate, to inform, to communicate, to motivate and to make people aware of development programs.

Here one can raise some questions: What is the relevance of looking at social change from a communication perspective? What can communicative standpoint provide us in addressing issues of social change? What are the differences between the various approaches to communication for social change and what is the political economy of these approaches? Understanding the different bases of communication for social change is foundational in setting up the criteria for evaluating these different approaches to social change, and connecting them to the praxis and politics of social change. ${ }^{4}$

Media has a large role to play in preventing and combating trafficking in Assam. It has a responsibility towards the society in mobilizing the public support and their involvement to fight the battle against trafficking. Media owes the ability to craft public opinion and hence media is a powerful tool for social change. In this era of globalization media has become the prime source of gathering information, so the significance of media in educating people about trafficking is indubitable. Media has a liability to ensure that

\footnotetext{
${ }^{3}$ Jaris Hanson and Uma Narula ed., New Communication Technologies in Developing Countries (New York: Routledge, 2012).

${ }^{4}$ Mohan J. Dutta, Communicating Social Change: Structure, Culture and Agency (New York and London: Routledge, 2011).
} 


\section{8 / Saket Kumar Bhardwaj \& Uttam Pegu}

Salesian Journal of Humanities and Social Sciences, Vol. X, No. 1. (May 2019) ISSN: 0976-1861 | DOI: 10.51818/SJHSS.10.2019.55-67 | Page: 55-67,

Section: Article

investigative journalism on human trafficking should be promoted. By writing an article, or broadcasting a drama or telecasting a short film, or advertisement on trafficking, media can shed light on the issues that often lie in darkness.

\section{Role of NGOs}

Like media, NGOs may be seen as vehicles for progressive change. In some parts of the world, NGOs have gained legitimacy because they are part of struggles against social evils. In being 'not governmental' they constitute vehicles for people to participate in development and social change in ways that would not be possible through government programs. In being 'not governmental' they constitute a 'space' in which it is possible to think about development and social change in ways that would not be likely through government programs. They constitute instruments for turning these alternative ideas, and alternative forms of participation, into alternative practices and hard outcomes.

\section{Trafficking in the Context of Assam}

Human trafficking has become a grim concern for Assam. In the year 2015, this state held the dubious record of most number of people trafficked among all the states of the country. According to the records available more than 6,000 children are still missing. From the year 2011 to the present, more than 760 cases of human trafficking are registered, where 1035 people became the victims of trafficking. 624 victims were rescued and 590 persons were arrested.

But the disquieting fact is that the number of trafficking cases has increased steadily over the years. In 2011 the number of registered cases were 54, the number gradually increased to 170 in 2015 and to 212 in the year 2016. In the month of January 2017, 22 cases of trafficking were registered. The most susceptible district of this province are Sonitpur, Kokrajhar, Kamrup(Rural), Tinsukia, Nalbari and Dhubri. ${ }^{5}$ It has been noticed that that the poorest section of the society has become the easy quarry of the traffickers. But there are

${ }^{5}$ The Assam Tribune, (Guwahati: Radha Govinda Baruah, 2017) Vol. 79, No. 115 
State Initiatives and the Role of Media in Mitigating Human Trafficking.. /59 Salesian Journal of Humanities and Social Sciences, Vol. X, No. 1. (May 2019) ISSN: 0976-1861 | DOI: 10.51818/SJHSS.10.2019.55-67 | Page: 55-67,

instances where persons displaced by ethnic clashes also became prey to the traffickers.

Number of cases of trafficking in Assam

\begin{tabular}{ccccc}
\hline Year & $\begin{array}{c}\text { No. of Cases } \\
\text { registered }\end{array}$ & $\begin{array}{c}\text { No. of } \\
\text { Persons } \\
\text { arrested }\end{array}$ & $\begin{array}{c}\text { No. of } \\
\text { Victims }\end{array}$ & $\begin{array}{c}\text { No. of } \\
\text { Victims } \\
\text { recovered }\end{array}$ \\
\hline 2011 & 54 & 67 & 75 & 64 \\
\hline 2012 & 99 & 77 & 177 & 122 \\
\hline 2013 & 118 & 130 & 153 & 130 \\
\hline 2014 & 90 & 53 & 113 & 51 \\
\hline 2015 & 170 & 162 & 228 & 167 \\
\hline 2016 & 212 & 99 & 266 & 95 \\
\hline Jan'2017 & 22 & 7 & 23 & 5 \\
\hline Total & 765 & 595 & 1,035 & 634 \\
\hline
\end{tabular}

(Source- The Assam Tribune, Vol. 79, No.115, May 1, 2017)

\section{Government Initiative}

The Government of Assam including the Police Department has taken several initiatives to combat human trafficking in the state. In order to improve coordination for the rescue of victims of commercial sexual exploitation and for the protection, counseling and rehabilitation, the State Government has constituted a State level Advisory Committee. There are 26 Special Juvenile Police Units and 27 Child Protection Units in Assam. Under the Integrated Child Protection Scheme (ICPS) there are 7 Shelter Homes in Assam. Assam Police in coordination with NIPCCD has organized workshops on Women and Child Rights/Trafficking in the year 2010-11. Regional workshops on Anti Trafficking are also being organized by the Assam Police. The Police department has initiated the Special Juvenile Police Unit (SJPU) in every district and designated Police Officers as Child Welfare Officers in every Police station. $^{6}$

The government has taken initiative to form networks with other NGOs, policy makers and police to facilitate rescue, rehabilitation

${ }^{6}$ RTI reply received from SSP CID, Assam. 


\section{0 / Saket Kumar Bhardwaj \& Uttam Pegu}

Salesian Journal of Humanities and Social Sciences, Vol. X, No. 1. (May 2019) ISSN: 0976-1861 | DOI: 10.51818/SJHSS.10.2019.55-67 | Page: 55-67,

Section: Article

and repatriation of the trafficked victims. The Assam Government has initiated several measures to implement the guidelines issued by the National Human Rights Commission on missing children. Assam police has also taken the initiative in maintaining the missing persons' data properly. The Advisories on Human Trafficking, Missing Children and Violence against Women and Children issued by the Ministry of Home Affairs, Government of India have been shared with the district officials for prioritization of the issue and to have more clarity on legal processes. The government has initiated awareness programmes as well. The Department of Social Welfare has initiated awareness programmes in villages in partnership with local panchayats across Assam since 2010. Vigilance committees have been constituted in trafficking-prone villages with Gram Pradhan, Gram Panchayat president, Anganwari workers, Asha workers, and school teachers to keep track of the numbers of girls migrated/missing from the village.

\section{Capacity Building measures by State Agencies}

First, the AHTU of Assam conducts two day Training of Trainers on combating human trafficking.

Second, AHTUs have been directed to sensitize the grass root agencies at District, Block and Panchayat level. 3. Optimum use of various schemes under MWCD like Swadhar, UJJWALA ICPS, ICDS, STEP (Support to Training and Employment of Women) and Sabla etc

Third, creating synergy among various government / nongovernment stakeholders agencies like social welfare, legal empowerment, health, NGOs, women's group, Information and Public Relations Department by holding periodical meetings and establishing the role of each agency in the AHTU by a nodal officer at the CID HQ.

Fourth, increase the functional utility of CWC by putting up the various cases before them for juvenile care and rescued victims. 
State Initiatives and the Role of Media in Mitigating Human Trafficking.. / 61 Salesian Journal of Humanities and Social Sciences, Vol. X, No. 1. (May 2019) ISSN: 0976-1861 | DOI: 10.51818/SJHSS.10.2019.55-67 | Page: 55-67, Section: Article

Fifth, AHTUs were directed to establish an Anti-Trafficking Committee at the village level to monitor the movement of children by involving Panchayati Raj institutions, VDPs (Village Defence Party) and Anganwadi workers etc. Maintenance of migration registers.

Sixth, establishment of fast-track courts for the cases pertaining to various social legislations.

\section{Assam Protection Mechanism at a Glance}

\begin{tabular}{|c|c|}
\hline Name & Number \\
\hline Anti-Human trafficking Units (Districts) & 10 \\
\hline District Child Protection Units & 7 \\
\hline Child Protection Homes & 7 \\
\hline Special Juvenile Police Units & 26 \\
\hline Child Welfare Committee & 27 \\
\hline Homes under Ujjawala P \& R Schemes & 12 \\
\hline Shelter Homes under Swadhar Scheme & 16 \\
\hline
\end{tabular}

(Source: Ministry of Women and Child, Government of India)

\section{Methodology}

Qualitative approach has been adopted to conduct this research, but in order to find the answers to certain research questions, Quantitative approaches have also been used. Rural people of Sonitpur District are selected for the purpose of the study. The total geographic area of Sonitpur district is 5324 sq.kms. Sonitpur is comprised of fourteen community development blocks comprising almost 1615 villages (sonitpur.gov.in). Seven blocks were randomly selected out of which one tea garden from each block was chosen arbitrarily for administering questionnaire and all the inhabitants of the villages formed the universe of the study. 20 inhabitants were selected randomly from each of the selected seven tea gardens. That made the selected 140 sample for the study.

Since this study is regarding those attributes of the people of the communities which cannot always be explained in terms of 


\section{2 / Saket Kumar Bhardwaj \& Uttam Pegu}

Salesian Journal of Humanities and Social Sciences, Vol. X, No. 1. (May 2019) ISSN: 0976-1861 | DOI: 10.51818/SJHSS.10.2019.55-67 | Page: 55-67,

Section: Article

numbers or quantity, hence a more qualitative approach has been adopted to conduct this research, using methods like observation, in-depth interviews, case study and group discussions. A simple random technique is used in this research.

In this research, focus group discussions were conducted, each with a different objective. In the focus group discussion, an interaction was held among community members who are in the position of opinion leaders of the community. These members were drawn from amongst leaders like volunteers working in NGOs, Anganbadi workers and teachers who have better understanding about the people of the community and their issues. In this research, such in depth interviews of certain members of the community including opinion leaders and NGO workers and victims from the study area are also taken.

\section{Case Study - People Action for Development (PAD)}

A Non-Governmental Organization, , rescued a girl of age of 17year from Delhi with a joint venture with Child Welfare Committee (CWC), Delhi. The girl who was a native of Rupajuli Tea Estate was lured by her companions and she went to Delhi with them. She was assured to get a job by her companion. But after reaching Delhi, she was kept in a basti by a male who also went with them to Delhi. That was the last time she saw her companions. The male took her to Jangpura by saying her that he will provide her with a job but he sold her there in exchange of a huge amount of money. The family of the girl did not register a missing complaint since they were not aware of the legal procedure. PAD came to know about the case and they started to find the girl immediately. The child protection committee of Gohpur helped them to contact CWS Delhi. And they were able to find the location of the girl and later with the help of CWC Delhi PAD rescued the girl. A local newspaper published the news of rescue of the girl. But the victim revealed that the media has published a lot of information about her. Now she and her family is facing the taunt of society and she is isolating herself from the society as she has to face demeaning behavior of the people from her village. 
State Initiatives and the Role of Media in Mitigating Human Trafficking.. / 63 Salesian Journal of Humanities and Social Sciences, Vol. X, No. 1. (May 2019) ISSN: 0976-1861 | DOI: 10.51818/SJHSS.10.2019.55-67 | Page: 55-67, Section: Article

\section{Case Study - Assam Police}

Assam police team rescued a 8 year old boy from Bahbari village .The child was a school dropout and his parents are daily-wage workers. With the consent of the parents an agent took the child to Arunachal Pradesh to work and a huge amount of money was exchanged between the parents of the child and the agent. When PAJHRA, a non-government organization came to know about the case the parents were warned and advised to bring back the child and also FIR was lodged. But according to a community mobilizer even after lodging the FIR police did not take action and so the mobilizer re-filed an FIR on September, 2015. Few days later the child was rescued by Assam police while working under a contractor in Arunachal Pradesh.

\section{Interpretative Analysis}

The demographic profile of the respondents showed that among them $17 \%$ of the respondents belong to the age group of 15 to 18 years, $36 \%$ of the respondents belong to the age group 18 to 24 years, $23 \%$ belong to the age group 25 to 34 whereas $22 \%$ belong to the age group 34 to 44 and rest comes under the age group of 45 to 54.More than half of them are employed i.e. $53 \% .21 \%$ of the respondents are uneducated and only 5\% had completed graduation. $21 \%$ of them earn below 1000 and 54\% earn 1000 to 2000, 18\% 3000-5000 and only $7 \%$ earn between 5000 to 7000 . In order to find out the awareness level of the respondents on trafficking and to determine their awareness on legal policies and to seek measure to raise awareness on legal issues related trafficking few questions were set in the questionnaire apart from the open ended questions.

First, from the in-depth interviews, focus group discussion and observation for around eight months it is clear that poverty is the main cause of trafficking in tea-plantation workers of Sonitpur district. According to the record one third of the total population is below poverty line. In the survey conducted for this research it has been seen that only $7 \%$ population earns above five thousand. 


\section{4 / Saket Kumar Bhardwaj \& Uttam Pegu}

Salesian Journal of Humanities and Social Sciences, Vol. X, No. 1. (May 2019) ISSN: 0976-1861 | DOI: 10.51818/SJHSS.10.2019.55-67 | Page: 55-67,

Section: Article

These people are lured by the traffickers by promising them a better future.

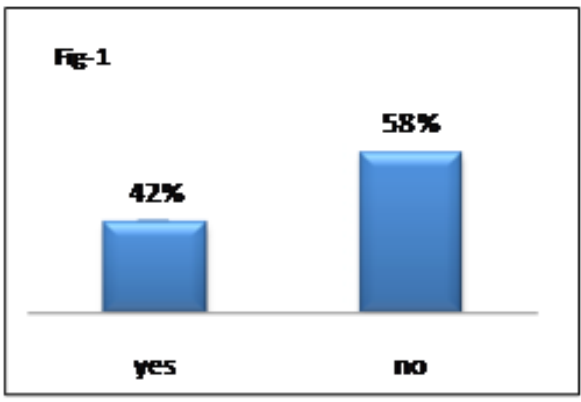

Fig. 1 shows the awareness among the respondents about trafficking. $42 \%$ said they know and understand the concept of trafficking and what measures should be taken. $58 \%$ do not know about trafficking.

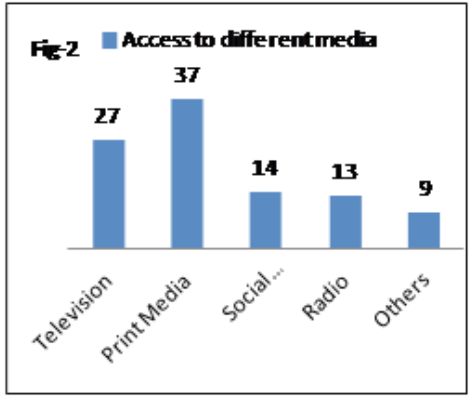

Fig. 2 shows awareness on trafficking / regarding legal policies.
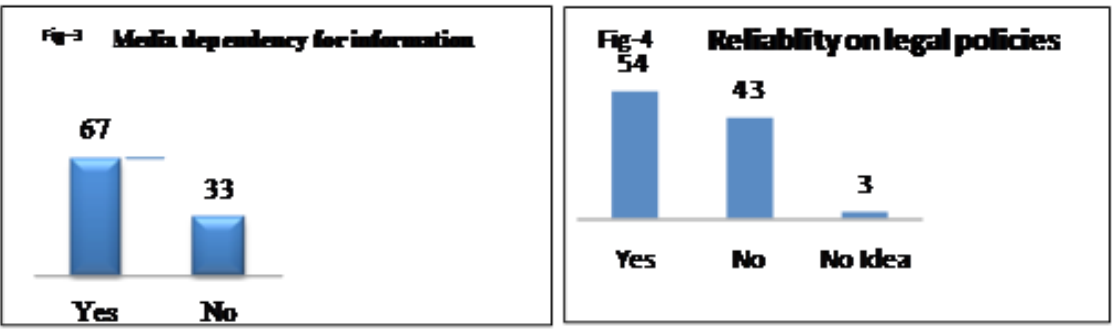

Fig. 3 represents the reliability of the Fig. 4 represents the respondents' respondents on the contents in dif- opinion on the reliability of the conferent legal policies. 54\% agreed that tents provided by different kind of they rely on legal policies and $43 \%$ media. $54 \%$ agreed that they rely on denied while $3 \%$ remained neutral. the media contents and $43 \%$ denied while $3 \%$ remained neutral. 
State Initiatives and the Role of Media in Mitigating Human Trafficking.. / 65 Salesian Journal of Humanities and Social Sciences, Vol. X, No. 1. (May 2019) ISSN: 0976-1861 | DOI: 10.51818/SJHSS.10.2019.55-67 | Page: 55-67, Section: Article

Second, flood is one of the destructive natural disasters in Assam. Due to flood not only people lose their home but also their livelihood. They are always in search of a way through which they can survive and traffickers use this as an opportunity to lure people. It was observed that most of the villages where the research was conducted have to face this calamity every year and during the interviews it was revealed that many families have lost their only livelihood, lost their agricultural plot to flood.

Third, Persistent poverty is a major factor. Many vulnerable women and girls are lured by promises of employment, and some parents are desperate enough to sell their daughters to traffickers. Rapid urbanization and the migration of large numbers of men into India's growing cities creates a market for commercial sex, as does a gender imbalance resulting from sex-selective abortion practices that has created a generation of young men who have little hope of finding female partners. India's affluence is also a factor, luring European women into India's sex trade. The caste system compounds the problem. ${ }^{7}$

Sonitpur comprises of people from different ethnicity. It is a place of diverse culture. So, often, clashes take place between two communities, sometimes for political agenda or for social intolerance. The societal structure, especially its economic backbone is often shattered due to such conflicts. Traffickers search for opportunity to lure people with fake job and a better future. And people easily fall in their trap.

\section{Summary of Findings}

The Adivasi community which is comprised of both tea and ex tea community is the ready prey for the traffickers. In the tea plantation the workers have to live a rigorous and stressful life. When someone promises a better life with less effort it is obvious that people fall for that. It was seen in the study that in many of the tea gardens the

7 The Editorial Board, "Sex Trafficking in India", The New York Times October 16, 2013, https://www.nytimes.com/2013/10/16/opinion/sex-trafficking-in-india. html. 


\section{6 / Saket Kumar Bhardwaj \& Uttam Pegu}

Salesian Journal of Humanities and Social Sciences, Vol. X, No. 1. (May 2019) ISSN: 0976-1861 | DOI: 10.51818/SJHSS.10.2019.55-67 | Page: 55-67,

Section: Article

temporary workers often go out in search of work when they do not have work in the garden. The young girls from the community are taken by agents to different metros as domestic help without the consent of their parents. Ex tea community people are the dailywage workers who live near the gardens. They also migrate to other places in search of work and these people also are easily lured.

Illiteracy is the main cause of trafficking of girls residing in the tea plantations of border areas of Sonitpur, Assam and they are not aware of the happenings around the world. They lack guidance from the family and they start dreaming of a colourful and modern life. They get deviated from the main stream and get affected by materialistic culture of the society. In that case many girls become an easy prey for the traffickers and without any knowledge they are sold to foreign countries.

Most of the respondents replied that they mainly follow newspaper and television. Interesting fact is that radio still has a wider audience in the community. They have community groups who perform street plays on various topics. They are playing a great role in creating awareness among people including their human rights.

According to the respondents they are close to media and media is accessible to all of them. Therefore it can easily create awareness on health rights among the people of the community. Due to the lack of awareness community people are still in the dark about their legal rights and legal policies related to trafficking. On the contrary, a number of superstitious beliefs are prevailing in the community.

On being asked if the community has been well represented by the existing mainstream media, it was pointed out that many issues are suppressed by the media. Lack of education or the willingness of the people to be educated was the biggest problem and the root of all other problems if the education scenario can be improved, it would be the solution to all other difficulties that are engulfing the community. 
State Initiatives and the Role of Media in Mitigating Human Trafficking.. / 67 Salesian Journal of Humanities and Social Sciences, Vol. X, No. 1. (May 2019) ISSN: 0976-1861 | DOI: 10.51818/SJHSS.10.2019.55-67 | Page: 55-67, Section: Article

The economic backgrounds of the respondents are not strong. Most of them live below poverty line. Natural disaster like flood is one of the main reasons of their economic grief according to the members participated in the FGD. Alcoholism among the men folk of the community often leading to domestic violence. The members claimed that many of the men in the community waste their time and money on alcohol, thus ignoring their family responsibilities. Apart from these, some other major issues of the people included problems of unemployment and population-explosion.

\section{Conclusion}

Human Trafficking is becoming a scorching woe of our civilization. In Assam, the problem of trafficking mostly happens in the border areas where people are predominantly illiterate and are alienated from the mainstream society. Media can raise awareness to inform people about this crime and can mobilize people to stop it. Media can also strengthen prevention by warning vulnerable groups and assuage the factors which make people vulnerable to trafficking. Also, it can enrich knowledge by a deeper understanding of the nature of trafficking through more data collection and analysis. Joint research initiative can also be taken up which can create an evidence based report on global trends. Most importantly a balanced outlook is important where in journalists and media persons provide information about the causes as well as suggest cures. News follow up is an important aspect wherein law enforcement officers must be taught how to identify victims of trafficking - particularly in areas outside of the commercial sex industry. More awareness and sensitivity to the trafficking of citizens is needed. ${ }^{8}$ Shortage of shelter homes for the rescued persons and lack of adequate facilities for their rehabilitation are few issues that came out from the focus group discussion that was conducted for this study. Media should have to focus on such issues and in most of the cases the rescued person is socially ostracized. Here also it is the responsibility of media to break such taboos, because media can influence its readers, audiences, and viewers in every aspect of their life.

${ }^{8}$ Aronowitz, Human Trafficking and Human Misery (Westport: Praeger Publishers, 2009). 